\title{
On religious and secular exemptions: A case study of childhood vaccination waivers
}

\section{Roland Pierik}

Paul Scholten Centre for Jurisprudence, Faculty of Law, University of Amsterdam, The

Netherlands

\begin{abstract}
This paper analyses exemptions to general law through the prism of vaccine waivers in the United States. All US states legally require the vaccination of children prior to school or daycare entry; however, this obligation is accompanied with a system of medical, religious, and/or philosophical exemptions. Nonmedical exemptions became subject of discussion after the 2015 Disneyland measles outbreak in California, which unequivocally brought to light what had been brewing below the surface for a while: a slow but steady decline in vaccination rates in Western societies, resulting in the reoccurrence of measles outbreaks. This can be traced back to an increasing public questioning of vaccines by a growing anti-vaccination movement. In reaction to the outbreak and the public outrage it generated, several states proposed-and some already passed-bills to eliminate nonmedical exemptions.

I analyze two questions. First, can legal exemptions from mandatory childhood vaccination schemes for parents who are opposed to vaccination (still) be justified? Second, should legal exemptions be limited to religious objections to vaccination, or should they also be granted to secular objections? Although the argument in the paper starts from the example of the US, it seeks to provide a more general philosophical reflection on the question of exemptions from mandatory childhood vaccination.
\end{abstract}

\section{Keywords}

Childhood vaccination, measles, legal exemption, toleration, liberalism, Disney measles outbreak, conscientious objections, accommodation, measles-mumps-rubella vaccine

\section{Corresponding author:}

Roland Pierik, Faculty of Law, Paul Scholten Centre for Jurisprudence, University of Amsterdam, P.O. box 1030, 1000BA Amsterdam, The Netherlands.

Email: r.pierik@uva.nl 


\section{Introduction}

The introduction of vaccines against infectious diseases has been one of the most important contributions to public health of the last century, ranking second only to the advent of clean water. Diseases like smallpox, polio, measles, mumps, rubella (MMR), and whooping cough were by far and away the major killers of human beings until the beginning of the 20th century. Nowadays, these diseases have been dramatically reduced or even eliminated in the Western world as a result of largescale vaccination programs. The major goal of such vaccination programs is the maintenance of the phenomenon of herd immunity, which occurs when a critical portion of a community is immunized against a contagious disease, the virus can no longer circulate in the population, so that the disease cannot gain foothold in that society. Indeed, it is through herd immunity that large-scale vaccination programs are so much more effective than individual vaccination.

A large majority of parents is convinced of the beneficial effect of vaccination on the health of their children and voluntarily enroll their children in such programs. However, since the introduction of the first vaccination programs in the beginning of the 19th century, a myriad of groups of parents have refused to vaccinate their children. Traditionally, the most well-known objectors are members of religious groups, predominantly Protestant Christian congregations, who argue that vaccination interferes with divine providence. In recent years, however, we can encounter a growing modern anti-vaccination movement, which argues that the dangers of vaccinations far outweigh their benefits. Unlike the more religious groups that are primarily inwardly oriented, this new anti-vaccination movement actively and successfully reaches out to new parents through anti-vaccination websites and TV celebrities. An important factor here is the $M M R$ vaccine causes autism controversy a decade ago, in the wake of the publication of Andrew Wakefield's article in The Lancet (Wakefield et al., 1998).

By now, Wakefield's claim has been fully debunked, The Lancet retracted his article two years after its publication due to suspicions of fraud and the association of scientific interest with litigation-driven profit motives (Deer, 2011). As a result, Wakefield has been stripped of his medical license and academic reputation. This controversy generated a huge industry of peer-reviewed research, none of which could corroborate the alleged vaccination-autism link (Jain et al., 2015; Taylor et al., 2014). Still, the suggested vaccine-autism link remains "the most damaging medical hoax of the last 100 years" (Flaherty, 2011: 1302). The claim was widely reported in the media and went viral on anti-vaccination websites.

After a long period in which the idea that vaccinations were beneficial and safe gained an ever-stronger foothold in western societies, this new movement heralded a turning point in the public trust in vaccines. This renewed public questioning of vaccines has led to a decline in vaccination rates, which ultimately culminated in the notorious 2015 Disneyland measles outbreak (see Majumder et al., 2015; Phadke et al., 2016). This was the first major measles outbreak in a decade, which spread throughout the US and Mexico and caused the death of a woman 
in Washington State (Izadi, 2015). ${ }^{1}$ How should liberal-democratic governments deal with such opposition to vaccination when it leads to compromised herd immunity and the re-emerging risk of outbreaks of a disease that for decades was assumed to be under control? ${ }^{2}$

Given their possible devastating effects, the state has a compelling interest in preventing (major) outbreaks of infectious diseases. Indeed, although it remains contested whether the liberal state should promote public health through welfare state institutions, it is undisputed that it should protect society against major threats to public health. Fighting infectious diseases is generally considered to be a classic government task. As part of that task several states legally require that children receive vaccinations against diseases like measles.

At the same time, many liberal political orders have endorsed a practice of ruleand-exemption as a way of dealing with legal obligations for morally sensitive issues - for example the exemption from compulsory military service for conscientious objectors. Childhood vaccination is a similarly sensitive issue: although a large majority of parents voluntarily consent to vaccination, a minority has strong objections against the practice. Historically, these legal exemptions originated as religious exemptions, available only to a very limited category of members of recognized religions. Over time, such exemptions became available to a wider category of parents, but up to today, many states explicitly distinguish religious from secular claims.

The issue of religious and secular exemptions has also gained considerable attention in current liberal political theory. On what grounds can exemptions to general law be justified? Why should conscientious objections justify dispensation from democratically adopted and generally applicable laws? In addition, if legal exemptions should be granted, should they be limited to religious convictions or should they also be granted to secular "strong beliefs" about the central importance and value of certain convictions, practices, and purposes? What feature of religion makes it so special that it deserves protection from state interference?

This paper analyses exemptions to general law through the prism of the topical and highly relevant case study of vaccine waivers in the United States. Although there is no federal regulation, all US states legally require the vaccination of children prior to school or daycare entry, but this requirement is accompanied with a system of medical, religious, and/or philosophical exemptions. These exemptions became subject to scrutiny after it emerged that the Disneyland measles outbreak was caused by substandard vaccination compliance due to high numbers of nonmedical exemptions. In reaction to the outbreak and the public outrage it generated, the state of California accepted a bill that eliminated all nonmedical exemptions. Besides California, legislators in other states have introduced bills that would make it harder for parents to opt out of vaccinating their kids. ${ }^{3}$ Thus these exemptions, though for a long time virtually undisputed, have now become the subject of intense public and political discussion.

This paper seeks to answer two questions. First, can legal exemptions from mandatory childhood vaccination schemes for parents who are opposed to 
vaccination (still) be justified? Second, should legal exemptions be limited to religious objections to vaccination, or should they also be granted to parents with secular objections? Although the argument in the paper starts from the US example, it seeks to provide a more general philosophical reflection on the question of exemptions from mandatory childhood vaccination and, consequently, a more general conclusion on exemptions in general. To focus the paper, I do not discuss mandatory childhood vaccination in general, but limit the argument to one disease, the measles, due to the turmoil the Dinseyland outbreak generated and because it is a "pure" example in this context. The measles is an extraordinarily contagious disease; its effects are quite severe and outbreaks are common enough to pose a significant threat to public health. Moreover, over time the vaccine has proven to be effective and safe. Finally, measles is a predominant example of a childhood disease because the first vaccination must be administered long before the age of reason kicks in. ${ }^{4}$

The paper is organized as follows. Section two explains why mandatory childhood vaccination is a necessity in currents days of vaccine hesitancy to maintain herd immunity. Section three conceptualizes legal exemptions in general, and section four discusses exemptions in the context of mandatory childhood vaccination. Sections five (on free-riders) and six (on the distinction between religious and secular objections) argue that it is impossible for liberal-democratic governments to substantially separate deeply held objections to vaccination from more superficial preferences. Section seven argues why an alternative approach, employing proxies to separate deeply held objections from more superficial preferences also fails. Section eight brings the various arguments together and concludes that a waiver system for mandatory childhood vaccination cannot be sustained: it either violates liberal-democratic tenets or it is incapable of limiting the number of exemptions in order to maintain robust herd immunity.

\section{Justifying mandatory vaccination: The maintenance of herd immunity}

The measles is a dangerous childhood disease for which there is no curative medicine; the only treatment available is prevention through vaccination. ${ }^{5}$ Once infected, the patient has to endure the disease and during this period she is susceptible to various risks. Out of every 1000 individuals who become infected, one or two will die from the disease; approximately one will develop encephalitis (a swelling of the brain that can lead to convulsions and leave the person deaf or with an intellectual disability) and as many as 50 get pneumonia. Even an "uncomplicated" course of the measles results in a week with a high fever, cough, sore throat, and a rash covering the entire body. ${ }^{6}$ Moreover, the measles is unusually contagious: an unvaccinated person exposed has a $90 \%$ chance of becoming infected with the disease. ${ }^{7}$ This implies that a patient is not only a victim of the disease, but also a vector in its further spread. Infected persons (can) infect others and contribute to outbreaks. As a consequence, the measles should not merely be discussed in terms 
of parent-child responsibilities, but primarily in terms of public health. Vaccination reduces the number of potential hosts - and thus carriers - of the disease in the population. The higher the vaccination rate, the harder it is for a disease to spread. The threshold of herd immunity for measles is achieved at $92-94 \%$, at which point major outbreaks are precluded (Orenstein et al., 2007: 1434).

As such, herd immunity not only protects the vaccinated but also several categories of persons who cannot be vaccinated for various medical reasons. The first category concerns infants and young children who have not yet completed the recommended childhood immunization schedule. Newborn babies have maternally derived antibodies that protect them against the measles and other diseases. Over time, however, the effect of these antibodies fades out and these children remain unprotected until their first vaccination. During this period, they can only be protected through the vaccination of the persons around them. The second category concerns persons for whom their vaccination turns out to be insufficiently effective because, in very rare cases, vaccinations do not mount an adequate immune response. There will always be a small percentage of vaccinated persons who remain unprotected; however, it is unclear who these individuals are until they get infected. The third category of persons concerns those who cannot undergo vaccination because they have certain forms of cancer, have a compromised immune system, or are likely to suffer from a serious allergic reaction.

Herd immunity thus not only protects individual vaccinated persons against the disease, it provides a higher-order societal protection because it prevents diseases from breaking out altogether. In that sense it is an important collective good and a major contribution to public health. Vaccinating healthy toddlers protects them from falling ill and prevents them from becoming vectors in the further spread of the disease. This is the main reason why countries like the US have endorsed mandatory vaccination programs in order to guarantee sufficiently high vaccination levels that protect the safety of vulnerable co-members of society who cannot protect themselves. Moreover, we have arrived at a point in time where we can conclude that there can be no genuine controversy on the risks of vaccination any more. ${ }^{8}$ A recent meta-analysis concluded that, after the administration of over 25 million vaccine doses, 33 cases of vaccine-triggered anaphylaxis, a potentially life-threatening allergic reaction, were confirmed (McNeil et al., 2016). Other research arrives at a similar conclusion: "there is evidence that some vaccines are associated with serious adverse events; however, these events are extremely rare and must be weighed against the protective benefits that vaccines provide" (Maglione et al., 2014: 325).

The state has a compelling interest in preventing (major) outbreaks of infectious diseases. The only way in which such outbreaks can be prevented is through the maintenance of robust herd immunity, and the only way herd immunity can be achieved is through mass vaccination. Until recently, outbreaks of the measles seemed abstract and remote in the western world. In that context it could seem to be an excessive use of governmental power to propose mandatory childhood vaccination. However, recent outbreaks have provided parents and the public with 
firsthand experience of the reality of these diseases and their harmful impact. When herd immunity cannot be taken for granted because of a growing vaccine denialism, the question arises whether a system of exemptions from mandatory childhood vaccination laws can be maintained.

\section{Conceptualizing legal exemptions}

Many liberal states have a cherished tradition of rule-and-exemption approaches as a way of dealing with legal obligations for morally sensitive issues. The most well-known example is that of exemption from compulsory military service for conscientious objectors. ${ }^{9}$ Mandatory childhood vaccination is a similarly sensitive issue. As discussed in the previous section, states have a compelling interest in preventing (major) outbreaks of infectious diseases and this has led certain states to implement mandatory childhood vaccination programs. A case in point is the United States. Although there is no federal regulation, all 50 states legally require vaccination of children prior to school or daycare entry. At the same time, this legal duty is accompanied with a system of exemptions. Three states - Mississippi, West Virginia, and (since 30 June 2015) California - only accept medical exemptions, e.g. only for children who are immunocompromised, those who have allergic reactions to vaccine constituents, and those who have a moderate or severe illness. All other states also offer non-medical exemptions: 28 states accept religious exemptions and 19 states offer religious and secular exemptions. ${ }^{10}$

How should the accommodation of exemptions be judged in the context of constitutional liberal democracies? At first sight, allowing exemptions seems to contradict a basic requirement of the idea of constitutional democracy. After all, clear application of the law, equal treatment, and the rule of law are paramount; law ought to be administered impartially and should have no favorites (Barry, 2001; Trigg, 2012). At the same time, the liberal state should acknowledge that facially neutral laws could nevertheless be disproportionally burdensome for certain citizens. Even though most parents comply voluntarily with the duty to vaccinate, some parents vehemently object to the practice. Mandatory vaccination implies that these parents have to go against their conscience or have to sacrifice deep commitments. And even though most other citizens do not share these convictions - or might even disagree with the convictions - they might nevertheless understand the importance of these convictions for the individual person, and the pain it would inflict upon parents if they have to act against their deepest commitments.

The question, then, is when universal application of law is paramount and under which circumstances exemptions should prevail. This is also a central question in current political-theoretical debates on legal exemptions. So-called muscular liberals rally around the idea of universal egalitarian law and argue that law, as the outcome of democratic deliberation and political processes should, in principle, be administered impartially and be binding on all. Barry's Culture and Equality (2001) is the notorious placeholder for this position. On the other hand, 
more tolerance-leaning liberals see legal exemptions to universal laws as the contemporary interpretation of the ancient-old liberal ideal of toleration (Dobbernack and Modood, 2013; Forst, 2012; Williams, 1996). Tolerance-leaning liberals argue that a blanket application of state law sometimes unduly burdens citizens who deeply disagree with the law because it contradicts squarely their conscience and deepest convictions. Allowing exemptions recognizes this fact by alleviating the particular burden of the members of these minority groups.

This paper does not aim to take a firm theoretical position in this more abstract political-theoretical debate. ${ }^{11}$ I think that the idea of accommodation is, ipso facto, not inconsistent with the central tenets of constitutional liberal democracy, especially in cases in which granting exemptions does not directly violate the fundamental rights of others. ${ }^{12}$ The fact that herd immunity can be maintained at a vaccination rate of $92-94 \%$ implies that there might be some room for exemptions from mandatory vaccination without endangering public health and the rights of others. I agree with Mahoney (2011: 311) that government should seek to accommodate minority practices in the most generous manner possible. We should be clear, though, what kind of right this is. It is not a straightforward and inviolable right of parents that nullifies the duty to vaccinate; instead, it is a toleration-based and conditional right to an exemption from a general legal duty, which can, and should, be revoked at the moment robust herd immunity is endangered.

In what follows, I accept that legal exemptions are, in principle, legitimate in liberal-democratic states, but that we should be sure that such exemptions are justified, all things considered, in two respects. First normatively: allowing exemptions should not collide with other central liberal-democratic values. Secondly, exemptions should be feasible practically: government agencies should be able to distinguish sincere objections against vaccination from so-called exemptions of convenience (Calandrillo, 2004), and they should be able to make this distinction by employing relatively straightforward legal norms. Narrowing down this approach to the subject of this paper: the first-order priority of government policy is to maintain and protect robust herd immunity. The second-order priority is to allow for exemptions if, and only if, they are feasible, both normatively and practically. Given these priorities, can a waiver system for mandatory childhood vaccination against the measles be maintained?

\section{Exemptions from mandatory vaccination}

The US waiver system for mandatory childhood vaccination became the subject of public and political dispute after the notorious 2015 Disneyland measles outbreak, especially when it became clear that the outbreak resulted from substandard vaccination compliance, which was caused by the high number of parents having received nonmedical exemptions (Colgrove and Lowin, 2016: 349; Majumder et al., 2015: E1). ${ }^{13}$ As a result, the Disneyland outbreak brought to the fore what was discussed longer in academic circles, namely, that most US states provide exemptions in a very generous, and rather unprincipled way. In theory, exemptions 
should only be given to a limited and very specific set of parents with genuine objections to vaccination. In practice, however, opting out of vaccination turned out to be remarkably simple. In a large number of states parents can forgo vaccinations by simply ticking a box on a pre-printed form, no questions asked. In addition, the vast majority of states do not enforce any limitations on exemptions, as 32 of 48 states that allow exemptions have not denied a single claim (Calandrillo, 2004: 434). This lenient way of enforcing mandatory vaccination law did little to stop the rising vaccine hesitancy that endangered herd immunity and increased the risk of measles outbreaks. In the 2013-2014 school year, the US Centers for Disease Control and Prevention found that most states failed to reach the target of having $95 \%$ of children entering kindergarten complete the two-dose MMR vaccine sequence - in the state of Colorado even less than $85 \%$ had received both doses of MMR (US Centers for Disease Control and Prevention, 2014).

The Disneyland outbreak led to an outpour of public indignation over the irresponsible behavior of non-vaccinating parents and the risks they present to public health. Popular media ironically emphasized that vaccination rates in wealthy Los Angeles schools were as low as in South Sudan (Khazan, 2014). In reaction to the outbreak, the state of California discussed Senate Bill 277 to eliminate all nonmedical exemptions. The proposal led, predictably, to heated opposition by opponents but was in the end accepted by a significant margin in the State Legislature (Nagourney, 2015). An initiative to a referendum to overturn the Bill fell (far) short of the number of signatures needed to put the issue on the ballot (McGreevy, 2015). In May 2016, the state of Vermont passed Bill H 98 which removes philosophical exemption and requires those seeking religious exemptions to review evidence-based educational material regarding immunizations. In June 2015, the American Medical Association explicitly endorsed stringent state immunization requirements to only allow exemptions for medical reasons, and legislators and public health professionals in nearly 30 other states are similarly working to get such reforms passed. ${ }^{14}$ At the same time, however, similar attempts in Oregon and Washington have failed - at least for the moment.

However, the fact that too many states have handed out exemptions too easily in the last decade, does not imply that a waiver system is, ipso facto, doomed to fail. As I will conclude later in this article, though, it might be an indication that such regulations are very hard - if not impossible - to implement in practice. Such a rule-and-exemption scheme can only be successfully implemented when (at least) three conditions are met. First, only a relatively small subset of persons should have objections to the duty as prescribed by law (Vallier, 2016). After all, allowing exemptions should not undermine or nullify the goal for which the specific legal duty is introduced. This implies that the large majority of citizens must have sufficient reason to endorse and abide by the law. Second, government agencies should be able to distinguish sincere deep objections from exemptions of convenience by relatively straightforward legal norms. And, thirdly, given the limited number of exemptions available, the distribution of this scarce good should not violate basic notions of justice. 
Applied to a waiver system for mandatory childhood vaccination, we can translate these conditions in the following way. The first-order priority is to maintain and protect robust herd immunity, which implies that the number of exemptions should be limited. The second-order priority is that the process of distinguishing sincere objections from exemptions of convenience should not violate central liberal values by, for example, undermining state neutrality, the secular character of law, or by privileging or discriminating against certain religious or other comprehensive doctrines. ${ }^{15}$ Only if these two priorities are met, a mandatory vaccination scheme with waivers is feasible.

The aim of vaccination policies is to protect all persons against infectious diseases, but this does not require that all persons have to be vaccinated. As mentioned above, herd immunity requires an overall vaccination coverage of $92-94 \%$, which implies that a limited practice of non-vaccination of $6-8 \%$ can be accommodated without sacrificing the rights of others, that is, the right of citizens to be protected against outbreaks of vaccine-preventable diseases. Since the risk of non-vaccination is cumulative in nature, herd immunity can be sustained, even if a certain percentage of parents refrain from vaccination.

However, the question remains how much room this leaves in practice for nonmedical exemptions. Firstly, a certain proportion of the $6-8 \%$ will consist of persons who are not (yet) protected for medical reasons, as described in section two: infants too young to be vaccinated, persons for whom the vaccination turns out to be insufficiently effective, and those who cannot undergo vaccination. There are good public health arguments to prioritize these medical exemptions over non-medical exemptions.

Secondly, even though it might be possible to achieve the average threshold vaccination rate in society overall, vaccination coverage is never spread evenly over the territory. Societies usually contain certain risk clusters in which vaccination rates fall below the level required to maintain herd immunity. The Dutch and US bible-belt, for example, are well known for harboring undervaccinated religious communities. This is a reflection of the more general phenomenon that people who share religious beliefs that object to vaccination will usually live in close proximity to each other and will have much interaction through churches, schools, and communal life (May and Silverman, 2003; Omer et al., 2008).

To sum up: the first-order priority is to prevent outbreaks, which requires robust state-wide herd immunity. This implies that the average vaccination rate must thus be higher than the standard $92-94 \%$ threshold to also assure herd immunity in pockets of under-vaccination. Moreover, a relatively large proportion of the exemptions are already taken up by the medical exemptions mentioned above (newborn babies, those who cannot undergo vaccination for medical reasons). Thus, although herd immunity for measles permits $6-8 \%$ of the population not to be vaccinated, the percentage thereof that can be allocated to non-medical exemptions is considerably smaller. This makes it even more urgent to restrict the number of non-medical exemptions. 


\section{Limiting the numbers of nonmedical exemptions: Keeping out free riders}

In order to limit the number of nonmedical exemptions, sincere objections against vaccination must be separated from exemptions of convenience. Before we can discuss more fine-grained arguments concerning religious and nonreligious exemptions, first we have to address the more mundane subject of free riders. As mentioned above, herd immunity is a collective good and, as such, it has two important characteristics. Firstly, it is non-excludable, that is, once achieved, it is impossible to exclude people from using the collective good. Herd immunity protects vaccinated and non-vaccinated persons alike. Second, a collective good is non-rivalrous, that is, one person's use of it does not limit the use of others. These characteristics of collective goods open the door to free riding: persons benefiting from a collective provision like herd immunity without contributing to the maintenance of the public good. As long as herd immunity is firmly established, children of vaccinating and non-vaccinating parents are equally protected against the disease, and this can explain the incentive to free ride. For one thing, taking one's kid to the doctor for a vaccination disrupts the daily routine for which one might have to take a morning off from work. And knowing that kids are always slightly feverish for a night or two after a vaccination, it seems rational to seek for such an exemption of

convenience. ${ }^{16}$ Since vaccinations are not provided free of charge by the US government, ${ }^{17}$ in some states it requires less effort to request an exemption than to fulfill the vaccination requirements (Salmon et al., 2006: 439). In addition, even though the standard vaccines like MMR have proven to be very safe, there is no such thing as a $100 \%$ risk-free medical intervention. It is inevitable that adverse reactions will occur in some cases, even when all reasonable precautions are taken in the manufacture and delivery of vaccinations. The great majority of side effects are local and minor - a sore arm or low-grade fever for a few days. As discussed above, more serious reactions to vaccines occur only in exceedingly rare circumstances, but still it is rational for parents to wish to avoid them, if possible, if one can assume herd immunity to be maintained by others.

However, free riding is, of course, inherently self-defeating: the more parents follow suit, the more herd immunity will be endangered and the more a waiver system is unsustainable. Some anti-vaccinators are very aware that their free ride can only be guaranteed as long as herd immunity is maintained by others. Dr Bob (Sears), a well-known US anti-vaccination celebrity, is blatantly honest in his advice to non-vaccinating patients: "I also warn them not to share their fears with their neighbors, because if too many people avoid the MMR vaccine, we'll likely see the disease increase significantly" (Sears, 2007: 96-97, as quoted in Navin, 2016: 143).

Needless to say, the putative immorality of free riding in this case is clear. Indeed, it is quite hard to justify the choice of parents to make use of a collective good that they value, but refuse to contribute their fair share to its maintenance. However, morally condemning the concept of free riding is one thing; it is quite 
another thing to come up with legal tools that capture the distinction between free riders from conscious objectors in workable legal criteria. Free riders know that their behavior is objectionable and are therefore not very likely to admit that they are free riding. They either follow Dr Bob or seek to hide the fact that they do not vaccinate, or present their refusal in terms of a conscientious objection and apply for philosophical or religious exemptions.

This demonstrates the first epistemic problem with waiver programs. They not only provide room for genuine grievances against vaccination but also for lessgenuine free-rider behavior because free riders are forced to present their exemption-claim in terms of genuine grievances, in order to be taken into consideration. It is precisely this behavior that disables laws and formal regulations to make a straightforward distinction between exemption claims based on genuine objections and exemptions of convenience.

\section{Separating religious and secular objections}

Since the introduction of the first smallpox vaccines, several groups of parents have refused to vaccinate their children. Traditionally, the most well-known objectors are members of religious groups. For example, Dutch Protestant-Christian congregations refuse vaccination because they consider it contrary to their religious convictions. They believe that God has predestined the fate of all human beings, including their health and the prevalence of diseases. They might not necessarily deny the effectiveness of large-scale vaccinations programs, but nevertheless prioritize other values, and conclude that vaccination is an "inappropriate meddling in the work of God." In the US, we find religious groups including Christian Scientists, Mennonites, and the Amish of which certain members also object to vaccination. For example, some Christian Scientists argue that disease is a spiritual phenomenon that should be healed through prayer instead of medication. They refuse vaccines because they believe that physical illness is an illusion of the material world and that prayer can help us to correct the false beliefs that give rise to illness.

These more traditional religiously inspired objectors to vaccination should be distinguished from the current, more secular wave of vaccine hesitancy, which primarily mobilizes parents and activists who are convinced that the risks of vaccination outweigh the purported benefits. ${ }^{18}$ In the last three decades, a vocal anti-vaccination movement has emerged, which conveys its message primarily through anti-vaccination websites. This is a multifaceted movement, including "spiritual" or "holistic" approaches, anthroposophists, homeopaths, and adherents of "natural healing" and "alternative healing." They dispute the medical consensus that vaccines are safe and effective; moreover, they question the selfevidence with which governments provide and promote large-scale vaccination programs. Some believe that a disease like measles could - in the case of otherwise healthy children - contribute to growth, development, and immunity building, which provide someone with greater resilience against diseases like cancer 
and allergies later in life. Others seek to carve out "all-natural" lives for their children, to maintain their "purity," or avoid contamination, assuming that vaccines contain toxic preservatives. Still others argue that current programs overwhelm a child's immune system because it is forced to handle too many vaccines too early in life. Even though none of these claims has been corroborated by evidence-based academic research, such groups are usually not bothered by that lack of scientific confirmation. To the contrary: the anti-vaccination movement is typically characterized by an aversion to "mainstream medical science" (Navin, 2016).

Should religious objections have more weight in such debates than secular objections? Again, the development in the US jurisprudence on the waiver system can help us to make sense of the distinction. ${ }^{19}$ Historically, the number of exemptions granted was limited because only a limited category was eligible: members of nationally recognized and established religious denominations. In 1971, several state courts widened the domain of exemptions "to everyone and anyone who claims a sincerely held religious belief opposed to vaccination-and not just those emanating from officially recognized religions." 20 Only in 1979 was this limitation to religion disputed in court, because religious exemptions "discriminate against the great majority of children whose parents have no such religious convictions."

It makes sense to lift the distinction between religious and secular claims for exemptions, because it does not fit with current, more secular ideals that governments should be neutral toward various (religious and secular) ideas of the good life (Pierik and Van der Burg, 2014). Moreover, the original distinction led to many odd exceptions. For example, although many secular claims were not even taken into consideration, an exemption claimed by a Jewish parent was allowed by a US court, even though nothing in Judaism objects to vaccinations (Calandrillo, 2004: 414, n 388). Another example is the fact that thousands of parents have qualified for religious exemptions by joining sham mail-order religions such as the Congregation of Universal Wisdom, through a contribution of \$75 and a $\$ 15$ fee for the official notification necessary to qualify for the exemption. ${ }^{21}$

Indeed, it is difficult for lawmakers and courts to come up with formal law and cogent court decisions to distinguish religious from more secular commitments because these commitments are typically insulated from ordinary standards of evidence and rational justification as employed in common sense and science (Leiter, 2013: 34). It is the religion, or the non-theistic equivalent in question that determines which commitments are legitimate causes for an exemption, not secular lawmakers or state judges (Macklem, 2008: 133). It is therefore quite an endeavor, if not impossible, for a liberal government to come up with a clear set of coherent conditions to separate legitimate, deep commitments from superficial preferences, and remain neutral to the various religious and secular philosophies of life.

More generally, the growing focus on state neutrality and secular law in the last decades affects the way such claims to exemptions are assessed. The more secular 
the assessment of exemption claims becomes, the harder it is to distinguish religious from secular convictions and, more importantly, to distinguish "strong beliefs" from "mere preferences." Within the liberal tradition, one that is so much determined by inter-Christian strife in Europe after the Reformation, such strong beliefs and the mere concepts of "conscience" and "conscientious objections" were limited to the-indeed quite contingent category of-members of nationally recognized and established religious Christian denominations and very much understood in Christian terminology and symbolism (Spinner-Halev, 2005; Waldron, 1987). In current, more secular, times, we need a more inclusive conception of the "strong beliefs" and "deep commitments" that provides normative status to convictions that individuals closely identify with and recognize as theirs, on the grounds of their "deep," "serious," "spiritual" nature. After all, it is because these religious and secular commitments meet the criterion of deep commitments that they justify exemptions from universal law. ${ }^{22}$

The transition to a more inclusive approach can be recognized in the way US and EU courts have assessed such claims. The European Court of Human Rights never provided a comprehensive definition of the term "religion" or "belief." Mainstream religions are readily accepted as belief systems. For other religions and personal belief systems, the Court merely employs formal criteria: the conviction must display "a certain level of cogency, seriousness, cohesion, and importance." 23 The latter terms have never been spelled out in case law, but Murdoch (2007: 11) explains that a specific act, i.e. objecting to vaccination, must relate to a weighty and substantial aspect of human life and behavior and be deemed worthy of protection in European democratic society. ${ }^{24}$ But nothing in these formulations separates religious from secular convictions. In United States v. Seeger, the US Supreme Court has, in matters of conscientious objection to military service, abandoned the religious/secular distinction by holding that an objection could be understood as "religious" when it is based on a "sincere and meaningful belief which occupies in the life of its possessor a place parallel to that filled by the God of those." 25 Following this jurisprudence, it is remarkable that several US states still only accept religious exemptions and deny secular exemptions; one would expect the distinction to collapse as soon as a secular parent in one of these states will make the case before the Supreme Court. However, it turns out that Seeger was an exception because the Supreme Court was interpreting the narrow terms of a statute rather than addressing the constitutional question of what should count as protected belief for purposes of the Free Exercise Clause of the First Amendment. As a result, judges have been reluctant to extend the constitutional protection of nonreligious deep, serious, moral commitments beyond narrowly circumscribed cases of conscientious objection to military service (Laborde, 2014: 68).

For liberal governments to comply with the contemporary demands of state neutrality - and for the US government to comply with the free exercise clause of the first amendment - the earlier theistic and substantial interpretation of the term "religious" must be abandoned and replaced by a more inclusive and formal one (Navin, forthcoming). This is also clear when we analyze the myriad of claims 
to exemptions from childhood vaccination today. Should modern objectors who, in one spiritual way or another, still adhere to Wakefield's debunked claim that vaccination causes autism be treated differently from Christians who argue that vaccination is an inappropriate meddling in the work of God, or from those who argue that diseases should be healed through prayer instead of medication, or from metaphysical thinkers who argue that vaccines undermine "purity" or hamper "spiritual growth of the person?" Yes, the former is based on a factual claim that contradicts evidence-based medicine, while the latter cannot be refuted scientifically, but this is, ipso facto, not sufficient as a criterion that can be employed by a neutral state for distinguishing the two claims, or to conclude that one justifies an exemption while the other does not.

Here the attempt to make meaningful distinctions between on the one hand, exemption-claims based on religious objections and secular objections and on the other hand, between sincere objections and mere exemptions of convenience, seem to end up in a free fall. The more law, policy, and adjudication have to rely on formal criteria like sincerity, cogency, or cohesion, the more a waiver system complies with the second-order priority, in that it does not privilege or discriminate against certain religious or other comprehensive doctrines. But when that distinction falls apart, it is also much harder to separate sincere objections from free-rider claims disguised as sincere objections. This, in turn, makes it much harder to fulfill the first-order priority: that a waiver system must be capable of limiting the number of exemptions to such an extent that herd immunity is not jeopardized. The more categories of exemption-claimers are acknowledged, the larger the number of (potential) claimants. If a liberal government aims to maintain herd immunity and if there is no neutral way of distinguishing insurmountable objections to vaccination from more superficial preferences, it will become impossible to design a waiver system that is both neutral to the several religions and secular ideas about the good life, as well as to be able to maintain robust herd immunity.

\section{Employing proxies}

In the previous section, I concluded that it is very hard to substantively identify genuine objections to vaccination and, consequently, to design law and policies to distinguish genuine objections from exemptions of convenience. One way to hold on to a waiver system is to give up the attempt to substantively assess parental convictions, but instead, to employ proxies to determine who can legitimately claim exemptions. The alternative service for objectors to the military service can serve as an example here. Recognized objectors have to contribute to the public good in another way, for example, by serving in educational or health care institutions. In addition, the alternative service usually takes a longer period than the military service, up to twice as long, in order to deter non-sincere objectors from taking the alternative route. In our case of exemptions from vaccination, a similar path can be taken. Vaccinating one's children contributes to the public good - it generates herd immunity - and is burdensome to the parents and the child. Alternative 
trajectories for vaccine objectors should contribute in a different way to the public good and/or should at least, in one way or another, be as onerous for parents as going through the vaccination procedure, in order to cut off the easy way out of vaccination. The question is to what extent such an approach can comply with the requirements formulated above: the first-order priority, limiting the number of exemptions in order to maintain and protect robust herd immunity; and the second-order priority, that the process of assigning exemptions should not privilege or discriminate against certain religious or other comprehensive doctrines.

Let me discuss three possible proxies. In the first, parents are required to follow a certain procedure before they are eligible for a vaccine waiver: to complete a set of educational sessions and to present their substantive opposition to vaccination before a formal review board. In this approach, the content of the objection is not substantially assessed; it is only marginally evaluated on whether it satisfies some basic formal requirements in order to entitle an exemption from mandatory vaccination. The basic idea is that, even though there is no substantive assessment of their actual arguments, the procedure forces parents to inform themselves about the dangers of non-vaccination, to formulate their objections against vaccination explicitly, and to defend them in a formal setting. Even though undergoing this procedure might not substantially alter the parents' beliefs about vaccination, at least it would make it harder for parents to forgo vaccination without being confronted with information on the possible dangers involved. Moreover, it would make the process of receiving a waiver more burdensome, which might at least deter some free riders.

A second proxy moves away from the problematic distinction between sincere objections and mere preferences by starting from an amoral conception of the public good of herd immunity in a specific community. It argues that, since herd immunity is such an essential public good, that all members of society can be expected to contribute. The most obvious contribution is to vaccinate one's children (and oneself). Those with objections to vaccinations have to contribute in another way to the public good, for example through paying a tax, for example financing vaccination schemes and to support vaccinations for low-income families. One advantage is that such a tax is much less intrusive and might therefore be more acceptable for those with religious or philosophical objections. A second advantage is that such an approach avoids the problem of assessing the true nature and depth of the objection. Your willingness-to-pay is taken as a proxy for the depth of your objection, and given the difficulty of determining sincere conscientious objections, willingness-to-pay might be the most neutral alternative. The level of taxation should yield at least the same burden as participating in a vaccination schedule - to make sure that opting out is not less burdensome than participating. Perhaps the charge could be based on the expected damage, according to the polluter paysprinciple. Another calculation method links the tax rate to the extent to which herd immunity is assured in a certain area. If the number of objectors within a specific community is small, the tax rate can be low, only covering the administrative fee required to uphold the system of exemptions, monitoring levels of herd immunity 
and possible outbreaks of infectious diseases. However, the larger the number of objectors in a specific area, the more the tax rate will rise. Above the threshold percentage to maintain herd immunity, some objectors have to lose out. Willingness-to-pay could, in a way, be the most neutral way to separate the wheat from the chaff.

Lotteries might provide a third proxy. Stone (2011) argues that lotteries are appropriately employed when it is essential to prevent bad reasons from affecting decisions about allocation of a certain good. If we conclude from the discussion in the previous section that it is impossible to substantially distinguish sincere objections from superficial preferences by relatively straightforward legal norms, we could distribute exemptions among parents who seek them through a lottery.

These proxies have the advantage that government is discharged from the impossible task of substantially assessing the content or the depth of an objection against vaccination. But all three proxies have their own problems. The first proxy might not provide enough of a barrier to exemption claims in order to secure robust herd immunity (first-order priority). After all, if parents know they only have to meet formal requirements but are in the end not assessed substantially, they know they just have to go through the motions to succeed. In addition, this proxy seems to be biased in favor of educated people, for whom it will be easier to formulate their substantive opposition than for less-educated people (secondorder priority). The second tax-proxy might have the ability to limit the number of exemptions by raising the tax to the threshold level, but it has the disadvantage that it is biased in favor of wealthier people (second-order priority). In an unequal society, a tax may not distinguish sincere from convenient objections, but rather pick out who is able to pay. If the tax is low, then we have done nothing to block the worries about exemptions of convenience for the better-off. If the tax is high, then only the well-off will be able to apply for exemptions. To the extent that we consider the current socio-economic inequality unjust, this proxy only reinforces these injustices. Moreover, it might be considered as insulting-buying one's right to follow one's conscience. The third lottery proxy has the disadvantage that it, in itself, does not solve the problem of free riding since every parent can subscribe to the lottery. As such it suffers from a reverse version of the second-order priority: is does not distinguish between groups that are relevantly different. Moreover, it does not take seriously the depth of the objections to vaccination. Genuine objectors seek for an exemption because they want their convictions to be taken seriously, not because they have won a lottery. As such it might provide exemptions to people with deep objections, but in such an insulting way that it will be despised and, as a result, maybe even rejected by persons with deep objections.

\section{Conclusion}

This paper discussed religious and secular exemptions to general law through the prism of waivers for mandatory childhood vaccination for the measles. Given that 
the measles is an extraordinarily contagious and quite severe disease and, given the fact that outbreaks are common enough to pose a significant threat to public health, government has a compelling interest in preventing outbreaks of vaccinepreventable contagious disease through maintaining robust herd immunity. The paper focused on legal regimes with mandatory measles vaccination schemes and discussed whether religious and secular exemptions can be maintained. The argument started from the idea that legal exemptions might ipso facto not be inconsistent with the central tenets of constitutional liberal democracy, but that they can only be accommodated when they are justified, all things considered, both from normative and practical perspectives. These conditions were translated into two priorities: the first-order priority that allowing such exemptions should not endanger robust herd immunity and the second-order priority that the distribution of this scarce good of exemptions should not violate central liberal-democratic values. A mandatory vaccination scheme with waivers is only justified when these two conditions can be met.

Since herd immunity against the measles only requires an average vaccination rate of $92-94 \%$, the first-order priority leaves some leeway for exemptions. However, since the vaccination coverage is spread unevenly over the territory and since a large proportion of the exemptions are already taken up by medical exemptions, the question is how much room the first-order priority leaves for nonmedical religious and secular exemptions. Concerning the second-order priority: where earlier arrangements, only providing exemptions to members of nationally recognized and established religious denominations, might have very been very successful in limiting the number of exemptions, this came at the expense of privileging the claims of certain groups over others. After all, the exempted category was not selected on the basis of the content of their objections, but because they were well established as religious - read Christian - groups in the US society. Given the great importance that is given nowadays to state neutrality and secular law, such a selective approach is outdated. A more egalitarian analysis of exemptions should be neutral to the various ideas of the good life - religious and secular - and should not privilege religious groups merely because they are historically well established in a specific society. Such a more inclusive approach makes it impossible to separate religious from secular objections to vaccination, which is also exemplified by the fact that the European Court of Human Rights and the US Supreme court have abandoned substantive assessments of objections in favor of more formal criteria like sincerity, cogency, or cohesion.

But once the assessment in terms of substantial criteria has been abandoned, it becomes quite difficult to exclude many of the current secular convictions that are employed to object to vaccination. After all, most of them are not merely objections to vaccination, but, instead, embedded in wider religious, spiritual, or holistic ideas of the good life. As such, not only does the distinction between religious and secular objections collapse, but the distinction between genuine and less genuine free-rider objections might dissolve as well. After all, since free riders are forced to present their objections in terms of genuine grievances in order to be taken into 
consideration, it will be very hard to design law and policies that can straightforwardly make the distinction between those objections that warrant exemptions, and those that do not.

This leads to a paradox for liberal-democratic exemption policies for mandatory childhood vaccination law: it seems to be impossible to satisfy the first-order priority and second-order priority simultaneously. Either the number of categories of objectors must be limited (and this can only be done by privileging some ideas of the good life over others thus violating the second-order priority) or the policy of accepting categories of objectors is neutral. However, that would most probably endanger robust herd immunity because it would open the door to too many exemption claims. This leads to the conclusion that it is very difficult to maintain vaccine waivers for the measles that are consistent with central liberal-democratic tenets and that are also able to maintain robust herd immunity.

\section{Acknowledgements}

Many thanks to Matteo Bonotti, Marc Davidson, Mark Navin, Lars Nickolson, Ingrid Robeyns, Jonathan Seglow, and Marcel Verweij for very helpful comments on an earlier draft of this paper.

\section{Declaration of conflicting interests}

The author(s) declared no potential conflicts of interest with respect to the research, authorship, and/or publication of this article.

\section{Funding}

The author(s) received no financial support for the research, authorship, and/or publication of this article.

\section{Notes}

1. The number of measles cases in the US has increased from no indigenous spread in 2000 to 189 cases in 2015. Centers for Disease Control and Prevention. Morbidity and Mortality Weekly Report: notifiable diseases and mortality tables. http:/www.cdc.gov/ $\mathrm{mmwr} /$ preview $/ \mathrm{mmwrhtml} / \mathrm{mm} 6452 \mathrm{md}$.htm?s_cid=mm6452md_w\#tab2 (accessed 20 April 2016).

2. When the term "liberal-democratic" is employed here, it refers to a political doctrine that favors liberal rights, democratic decision making, and the rule of law.

3. For an overview of the various legislative proposals, see http://www.motherjones.com/ politics/2015/02/vaccine-map-exemption-bills (accessed 7 March 2016).

4. This paper focuses on one single disease because diseases differ significantly in their prevalence, their contagiousness, and the danger they pose to health once infected. However, I maintain that similar arguments can be made for diseases like mumps, polio, and whooping cough. A practical problem is that the measles vaccine is part of the measles-mumps-rubella (MMR) triple vaccine, but that does not have to undermine this normative argument.

5. This section draws upon, and incorporates material from Pierik (2017). 
6. http://www.cdc.gov/measles/about/complications.html (accessed 12 January 2016). The last major measles outbreak in the Western world was in France between 2008 and 2011, in which 10 patients died and almost 5000 patients were hospitalized, including 1023 for severe pneumonia and 27 for encephalitis/myelitis (Antona et al., 2013).

7. For this reason, Opel et al. (2016) have argued that the measles pose a more important problem than other vaccine-preventable infectious diseases. For a critique see: Byington et al. (2016).

8. This vaccine denialism is very similar to global warming denialism with one important difference: research on global warming emerged relatively recently and is confronted with many uncertainties, whereas research on the MMR vaccine is very robust and became well established during the last century.

9. For the (dis)analogy between conscientious objection against conscription and vaccination, see Salmon and Siegel (2001: 292).

10. For an overview of the regulation per state, see: http://www.vaccinesafety.edu/cc-exem. htm.

11. Some central contributions to this debate are: Greene (2009); Jones (2014); Mahoney (2011); Sandberg and Doe (2007); Seglow (2011); Shorten (2015); and Vallier (2016).

12. For a discussion of exemptions that do violate the rights of others and, thus, are much more contested, see Cohen (2015).

13. The practice of granting exemptions is also well established within Europe-for the thorough discussion, see Calder and Ceva (2011). However, it does not play a role at all in this vaccination discussion. Childhood vaccination is either recommended but voluntary, for example in the Netherlands, or certain vaccinations are compulsory without exemptions. For example, the MMR vaccination is mandatory in many Eastern European states, including Bulgaria, the Czech Republic, Hungary, Poland, Romania, Slovakia, and Slovenia. For an overview of mandatory and recommended vaccination schemes in Europe, see Haverkate et al. (2012).

14. http://www.ama-assn.org/ama/pub/news/news/2015/2015-06-08-tighter-limitationsimmunization-opt-outs.page, assessed 30 May 2016.

15. Although concepts like state neutrality and secular law are contested within the liberal tradition (cf. Pierik and Van der Burg, 2014), it is beyond dispute that government cannot randomly distribute exemptions from mandatory law by including some groups and excluding others without good arguments justifying this distinction.

16. However, as Navin (2016: 135-161) rightly concludes, the term free rider might be somewhat harsh for parents who are forced to work multiple jobs to make ends meet and are dependent on public transport to arrive at the doctors' office to receive the vaccination for their child.

17. Childhood vaccination is supported, though, by government programs that support low-income families.

18. The historian Mark Largent (2012) emphasizes that there are only a very few historical links between the "current" anti-vaccination movement and previous movements.

19. For an overview, see Calandrillo (2004: 386-387).

20. Dalli v. Bd. of Educ., 267 N.E.2d 219, 222-23 (Mass. 1971), as quoted in Calandrillo (2004: 415).

21. The main article of faith of the Congregation, quite characteristically, is that the injection of any medication or other man-made substance would violate the sanctity of the body. 
22. One interesting way to deal with this issue is Cécile Laborde's disaggregation approach (2015: 593-599).

23. Campbell and Cosans v. The United Kingdom, App. Nos. 7511/76, 7743/76, Eur. Ct. H.R., at 12-13 (1982).

24. Article 9 ECHR protects the right of a person to manifest belief through "worship, teaching, practice and observance." A "manifestation" implies a perception on the part of the person involved that a course of action is prescribed or required (Murdoch, 2007: 15). Up to now there is no case law that has settled whether the right to hold the belief that mandatory vaccination should be resisted also implies the right to manifest that belief. Although this uncharted territory is quite relevant in the discussion on exemptions from mandatory vaccination, it would affect both religious and secular claims and is therefore irrelevant for this discussion at hand.

25. United States v. Seeger, 380 US 163 (1965: 176).

\section{References}

Antona D, Lévy-Bruhl D, Baudon C, et al. (2013) Measles elimination efforts and 20082011 outbreak, France. Emerging Infectious Diseases 19(3): 357-364.

Barry B (2001) Culture and Equality: An Egalitarian Critique of Multiculturalism. Cambridge, MA: Harvard University Press.

Byington CL, Clayton EW and Edwards KM (2016) Childhood vaccine exemptions: A broader perspective is required. Pediatrics 137(4): e20160189.

Calandrillo SP (2004) Vanishing vaccinations: Why are so many Americans opting out of vaccinating their children? University of Michigan Journal of Law Reform 37(2): 353-440.

Calder G and Ceva E (2011) Diversity in Europe: Dilemmas of Diffential Treatment in Theory and Practice. London: Routledge.

Cohen J (2015) Freedom of Religion Inc.: Whose sovereignty? Netherlands Journal of Legal Philosophy 44(3): 169-210.

Colgrove J and Lowin A (2016) A tale of two states: Mississippi, West Virginia, and exemptions to compulsory school vaccination laws. Health Affairs 35(2): 348-355.

Deer B (2011) How the vaccine crisis was meant to make money. British Medical Journal 342(7789): 136-142.

Dobbernack J and Modood T (eds) (2013) Hard to Accept New Perspectives on Tolerance, Intolerance and Respect. Basingstoke: Palgrave.

Flaherty D (2011) The vaccine-autism connection: A public health crisis caused by unethical medical practices and fraudulent science. Annals of Pharmacotherapy 45(10): 1302-1304.

Forst R (2012) Toleration. In: Zalta EN (ed) The Stanford Encyclopedia of Philosophy (Summer 2012 Edition). https://plato.stanford.edu/archives/sum2012/entries/toleration/.

Greene A (2009) Three theories of religious equality. . . and of exemptions. Texas Law Review 87(963): 963-1007.

Haverkate M, D'Ancona F, Giambi C, et al. (2012) Mandatory and recommended vaccination in the EU, Iceland and Norway: Results of the VENICE 2010 survey on the ways of implementing national vaccination programmes. Euro Surveillance 17(22): 12-17.

Izadi E (2015) The U.S. just recorded its first confirmed measles death in 12 years. The Washington Post, July 2. Retrieved from http://www.washingtonpost.com/news/to-yourhealth/wp/2015/07/02/the-u-s-just-recorded-its-first-confirmed-measles-death-in-12years/. 
Jain A, Marshall J, Buikema A, et al. (2015) Autism occurrence by MMR vaccine status among US children with older siblings with and without autism. The Journal of the American Medical Association 313(15): 1534-1540.

Jones P (2014) Accomodating religion and shifting burdens. Criminal Law and Philosophy 10(3): $515-536$.

Khazan O (2014) Wealthy L.A. schools' vaccination rates are as low as South Sudan's. The Atlantic, 16 September. Retrieved from https:/www.theatlantic.com/health/archive/ 2014/09/wealthy-la-schools-vaccination-rates-are-as-low-as-south-sudans/380252/.

Laborde C (2014) Equal liberty, nonestablishment and religious freedom. Legal Theory 20(1): $52-77$.

Laborde C (2015) Religion in the law: The disaggregation approach. Law and Philosophy 34(6): 581-600.

Largent MA (2012) Vaccine: The Debate in Modern America. Baltimore: Johns Hopkins.

Leiter B (2013) Why Tolerate religion? Princeton: Princeton University Press.

Macklem T (2008) Independence of Mind. Oxford: Oxford University Press.

Maglione MA, Das L, Raaen L, et al. (2014) Safety of vaccines used for routine immunization of US children: A systematic review. Pedeatrics 134(2): 325-337.

Mahoney J (2011) A democratic equality approach to religious exemptions. Journal of Social Philosophy 42(3): 305-320.

Majumder MS, Cohn EL, Mekaru SR, et al. (2015) Substandard vaccination compliance and the 2015 measles outbreak. JAMA Pediatrics 169(5): 494-495.

May T and Silverman RD (2003) Clustering of exemptions as a collective action threat to herd immunity. Vaccine 21: 1048-1051.

McGreevy P (2015) Not enough signatures: Vaccine opponents fall short in ballot effort. Los Angels Times, 30 September. Retrieved from http://www.latimes.com/local/political/ la-me-pc-vaccine-law-foes-fall-short-in-petition-drive-for-referendum-20150930-story. html.

McNeil MM, Weintraub ES, Duffy J, et al. (2016) Risk of anaphylaxis after vaccination in children and adults. Journal of Allergy and Clinical Immunology 137(3): 868-878.

Murdoch J (2007) Freedom of Thought, Conscience and Religion: A Guide to the Implementation of Article 9 of the European Convention of Human Rights: Council of Europe Human Rights Handbooks. Retrieved from http://www.echr.coe.int/ LibraryDocs/DG2/HRHAND/DG2-EN-HRHAND-09(2007).pdf.

Nagourney A (2015) California mandates vaccines for schoolchildren. New York Times, 30 June, A19.

Navin M (forthcoming) Prioritizing religion in vaccine exemption policies. In: Vallier K and Weber M (eds) Religious Exemptions. New York: Oxford University Press, pp. 1-17.

Navin M (2016) Values and Vaccine Refusal: Hard Questions in Epistemology, Ethics and Health Care. New York: Routledge.

Omer SB, Enger KS, Moulton LH, et al. (2008) Geographic clustering of nonmedical exemptions to school immunization requirements and associations with geographic clustering of pertussis. American Journal of Epidemiology 168(12): 1389-1396.

Opel DJ, Kronman MP, Diekema DS, et al. (2016) Childhood vaccine exemption policy: The case for a less restrictive alternative. Pediatrics 137(4): e20154230.

Orenstein WA, Strebel PM and Hinman AR (2007) Building an immunity fence against measles. The Journal of Infectious Diseases 196(10): 1433-1435. 
Phadke VK, Bednarczyk RA, Salmon DA, et al. (2016) Association between vaccine refusal and vaccine-preventable diseases in the United States. A review of measles and pertussis. Journal of the American Medical Association 315(11): 1149-1158.

Pierik R (2017) Mandatory vaccination: An unqualified defense. Journal of Applied Philosophy1-18. Epub ahead of print 18 May 2016. DOI:10.1111/japp.12215.

Pierik R and Van der Burg W (2014) What is neutrality? Ratio Juris 27(4): 513-532.

Salmon D, Teret S, MacIntyre R, et al. (2006) Compulsory vaccination and conscientious or philosophical exemptions: past, present, and future. The Lancet 367(9508): 436-442.

Salmon DA and Siegel AW (2001) Religious and philosophical exemptions from vaccination requirements and lessons learned from conscientious objectors from conscription. Public Health Reports 116(4): 289-295.

Sandberg R and Doe N (2007) Religious exemptions in discrimination law. The Cambridge Law Journal 66(2): 302-312.

Seglow J (2011) Theories of religious exemptions. In: Calder G, Ceva E (eds) Diversity in Europe: Dilemmas of Diffential Treatment in Theory and Practice. London: Routledge, pp.52-64.

Shorten A (2015) Are there rights to institutional exemptions? Journal of Social Philosophy 46(2): 242-263.

Spinner-Halev J (2005) Hinduism, Christianity, and liberal religious toleration. Political Theory 33(1): 28-57.

Stone P (2011) The Luck of the Draw: The Role of Lotteries in Decision Making. Oxford: Oxford University Press.

Taylor LE, Swerdfeger AL and Eslick GD (2014) Vaccines are not associated with autism: An evidence-based meta-analysis of case-control and cohort studies. Vaccine 32(29): 3623-3629.

Trigg R (2012) Equality, Freedom, and Religion. Oxford: Oxford University Press.

US Centers for Disease Control and Prevention (2014) Vaccination coverage among children in kindergarten-United States, 2013-14 school year. Morbidity and Mortality Weekly Report (MMWR) 63(41): 913-920.

Vallier K (2016) The moral basis of religious exemptions. Law and Philosophy 35(1):1 -28.

Wakefield AJ, Murch SH, Anthony A, et al. (1998) Ileal-lymphoid-nodular hyperplasia, non-specific colitis, and pervasive developmental disorder in children. The Lancet 351(9103): 637-641. Accessed 28 January 2010.

Waldron J (1987) Theoretical foundations of liberalism. The Philosophical Quarterly 37(147): 127-150.

Williams B (1996) Toleration: An impossible virtue? In: Heyd D (ed.) Toleration: An Exclusive Virtue. Princeton: Princeton University Press, pp.3-18. 